\title{
A CONTRIBUIÇÃO DA ESTRATÉGIA COMO PRÁTICA PARA O ESTUDO DA FORMAÇÃO DE ESTRATÉGIAS EM UNIVERSIDADES
}

\author{
THE CONTRIBUTION OF THE STRATEGY AS A PRACTICE FOR THE STUDY \\ OF STRATEGY TRAINING IN UNIVERSITIES
}

\author{
Haroldo Andriguetto JUNIOR ${ }^{1}$
}

RESUMO: As universidades, classificadas como organizações complexas, possuem uma forma especial de atuar, pela multiplicidade de seus objetivos, aliados a heterogeneidade de seu grupo profissional. O objetivo deste estudo teórico é examinar a contribuição da Estratégia como Pratica para a formação das estratégias em Universidades. Como resultado do estudo foi elaborado um quadro conceitual guia para pesquisas futuras. Como conclusões, obteve-se que a Estratégia como Prática é fundamental para aprofundar o processo estratégico das organizações universitárias, possuindo substantivas implicações para os estudos dessas organizações pelo forte enfoque nas atividades micro, ou seja, nas práticas estratégicas diárias, nas rotinas, nas negociações, entre outras de extrema relevância para essas organizações, já que a estratégia fica, em geral, a mercê dos especialistas ou praticantes.

PALAVRAS-CHAVES: Estratégia como prática. Universidades, Estratégia.

ABSTRACT: Universities are classified as complex organizations, have a special way of acting, the multiplicity of its objectives, coupled with heterogeneity of their professional group. The aim of this theoretical study is to examine the contribution of the Strategy as Practice for the formation of Universities strategies. As a result of the study was prepared a guide conceptual framework for future research. As conclusions, it was found that the Strategy as Practice is fundamental to deepen the strategic process of university organizations having substantial implications for studies of these organizations by the strong focus on micro activities, namely the daily strategic practices, routines, in negotiations among other very important for these organizations, as the strategy it is generally at the mercy of experts or practitioners.

KEY WORDS: Strategy as practice, University, Strategy.

\section{Introdução}

As Universidades são organizações atípicas, que apresentam características diferenciadas das demais burocracias ditas tradicionais. Apresentam características

${ }^{1}$ Haroldo Andriguetto Junior, mestre em administração e diretor escolar. Rua João Angelo Cordeiro, 975

- São José dos Pinhais - PR - 83.005.570 - E-mail: haroldo.andriguetto@ hotmail.com 
específicas: são multifinalistas, com objetivos conflitantes, difusos e ambíguos. Revelam-se complexas, pois tratam de um produto altamente intangível, o conhecimento, resultando em um trabalho essencialmente qualitativo. Possuem tecnologias múltiplas e grandes sensibilidade a fatores ambientais que interferem diretamente em sua estratégia. Ainda assim, classificam-se como organizações profissionais, que apresentam boa parte do processo decisório fragmentado em grupos por área de competência profissional. Ainda assim, a literatura apresenta essas organizações como sistemas frouxamente articulados e como anarquias organizadas, onde sua estratégia pode ser percebida como um processo racional, político e simbólico.

A estratégia como prática, por outro lado, revela-se uma Teoria que busca investigar como a estratégia é praticada, de fato, nas organizações. Nessa teoria, o foco de análise está sobre as microatividades dos indivíduos que compõem a organização, como rotinas, práticas estratégicas, reuniões, barganhas, negociações, entre outros. Está centrada nas práxis, práticas e nos praticantes que, em conjunto, fazem a estratégia.

Considerando o exposto, este estudo teórico tem como objetivo examinar a contribuição da Estratégia como Prática para a análise da formação das estratégias em Universidades. Além disso, explicitando um quadro conceitual guia para pesquisa de formação de estratégias em universidades, considerando os pressupostos da Estratégia como Prática, relacionando as implicações da estratégia como prática com os principais conceitos publicados sobre a estratégia, o sistema, o processo decisório e a dinâmica interna das organizações universitárias.

Com esta pesquisa, pretende-se contribuir para os estudos organizacionais, principalmente no caso das Universidades, organizações de tal complexidade, particularidade e importância no contexto atual.

\section{Desenvolvimento}

\section{Estratégia como Prática social}

Tradicionalmente a estratégia tem sido tratada nos estudos como algo dado e pronto para as organizações. Whittington (2006, p.613, tradução do autor) ressalta a essência da Estratégia como Prática e sua preocupação distinta das demais abordagens sobre estratégia, quando enfoca que 
tradicionalmente, a disciplina de estratégia tem tratado a estratégia como uma propriedade de organizações: uma organização tem uma estratégia de algum tipo ou outro. Cada vez mais, no entanto, a estratégia está a ser encarada também como uma prática: a estratégia é algo que as pessoas fazem.(WHITTINGTOM, 2006, p.613)

A medida que a estratégia é abordada a partir do que as pessoas fazem, dois desafios principais são lançados, segundo Whittington (2006): o primeiro deles é um convite à forte observação e atenção as microatividades ou as atividades das pessoas no interior das organizações; e o segundo desafio diz respeito ao impacto dessas ações conjuntas na sociedade em geral. Por isso, segundo Golsorkhi et al. (2010, p.1), são comuns em estudos de Estratégia como Prática representantes de algumas bases teóricas, como Wittgenstein (1951); Foucault (1977); Dreyfus (1991); Tuomela (2005) oriundos da filosofia; Giddens (1984), Certeau (1984), oriundos da sociologia; os antropólogos Bourdieu (1996), Ortner (2006), os teóricos da atividade Vygotsky (1978), Engeström et al (1999), analistas como Fairclough (2003), e outros.

A análise da Estratégia como Prática centra-se, segundo Golsorkhi et al (2010, p.1) no nível micro de atividades sociais, nos processos, práticas e rotinas que caracterizam a estratégia organizacional. Essa forma de ver a Estratégia como Prática tem desenvolvido um novo olhar sobre as organizações e como as estratégias são formadas. Golsorkhi et al. (2010, p.1) ressalta que a Estratégia como prática pode ser considerada como uma alternativa para a pesquisa em estratégia, quando tenta desviar o foco sobre os efeitos das estratégias em relação ao desempenho para uma análise mais abrangente, em profundidade, se atentando para o que, de fato, realmente ocorre no planejamento estratégico, implementação de estratégias e outras atividades que lidam com a estratégia.

Whittington (2006, p.617) cita que um dos objetivos principais da Estratégia como Prática é aprofundar as conexões entre o que realmente se passa dentro das organizações e os mais diversos fenômenos externos, na tentaiva de cada vez mais se aproximar da realidade social e da formação da estratégia.

Literalmente, como cita Golsorkhi et al (2010, p.1), trata-se de ir em busca da "caixa preta"da estratégia, no entanto, se diferenciando de métodos tradicionais, geralmente de base econômica e análises estatísticas, buscando recorrer a teorias diferenciadas e escolhas metodológicas mais robustas. 
A visão de Estratégia como Prática observa questões diferentes das tradicionais abordagens estratégicas. A luz dessa teoria, três razões principais explicitadas por Golsorkhi (2010, p.2), são possibilitadas ao pesquisador:

a) constituir uma oportunidade de analisar o nível micro social das atividades e sua formação em um contexto social real ou campo. Assim, uma abordagem prática permite uma maior aproximação da realidade social;

b) romper com abordagem do individualismo metodológico, enfatizando que as atividades precisam ser entendidas como sensibilizadas pelas práticas vigentes ou dominantes no campo em questão. Assim, uma abordagem prática para a estratégia não deve apenas focar os comportamentos ou ações dos gestores, mas procurar analisar como essescomportamentos ou ações estão relacionados com essas práticas;

c) permitir associar como a ação social está ligada com a estrutura e a agência. Os estudos da prática, essencialmente, investigam o porquê e como ação social, por vezes, acompanha e reproduz as rotinas, regras e normas e às vezes acontece apesar destas.

De acordo com o autor, o nível de análise da Estratégia como Prática vai além da análise estratégica trivial apresentada na literatura. Há um pressuposto principal de que há uma realidade subjetiva, uma sociedade, com atores interagindo, interpretando e modificando suas práticas e interferindo em seu campo constantemente em um processo recursivo.

Whittington (2006, p.3) faz importantes questionamentos que revelam o grau de análise e a essência da pesquisa em Estratégia como Prática:

Como o padrão das práticas possuem impacto sobre as atividades estratégicas, como são produzidas as práticas estratégia influentes; que tipos de profissionais são os mais importantes na transferência e, ocasionalmente, na inovação das estratégias e, finalmente, como é que as pessoas se tornam praticantes da estratégia eficaz? (WHITTINGTON, 2006, p.3)

O autor comenta que a preocupação da Estratégia como Prática está centrada, primeiramente, em como "campos" sociais (Bourdieu,1996) ou "sistemas" (Giddens, 2003) definem as práticas dominantes, ditas como entendimentos compartilhados de, normas culturais, linguagens e procedimentos que permitem a atividade humana; por segundo a pesquisa prática busca efetivamente investigar o que acontece na prática, os múrmurios do cotidiano, as rotinas, a "razão prática" pela qual determinada situação é 
vivida naquele determinado momento; e por terceiro busca uma reflexao sobre as pessoas e como suas habilidades de transformar os espaços sociais são articuladas.

Golsorkhi et al. (2010), ressalta que atores de um sistema social podem ser criativos, reflexivos e com potencial para mudança. São percebidos como intérpretes das práticas que acontecem no cotidiano, que se utilizam de negociações, truques, artifícios e manobras para atuar na vida cotidiana.

A idéia central, segundo o autor, é que os focos de concentração são sobre as práticas reais que constituem a estratégia e o fazer estratégia ou "estrategizar", conhecido também como strategizing, sem deixar de lado a reflexão que se faz sobre a posição social, perspectivas e práticas do pesquisador.

Portanto, de acordo com Jarzabkowski, Balogun e Seidl (2007, p.8), a estratégia é percebida como um conjunto de atividades socialmente construídas. Para que o conceito não fique muito amplo e englobe todos os tipos de atividades sociais, os autores alertam que o objetivo de estudo é se concentrar nas atividades que se baseiam nas práticas estratégicas. Assim, para Jarzabkowski, Balogun e Seidl (2007, p.8):

Estratégia é um tipo específico de atividade que está relacionada com práticas específicas, tais como planejamento estratégico, as revisões anuais, seminários sobre estratégia e os seus discursos associados [...] Assim, tal como a ciência pode ser definida como as actividades que se baseiam nas práticas científicas (por exemplo, métodos , instrumentos linguísticos, científicos -Latour, 1987), a estratégia pode ser definida como as atividades que se baseiam em determinadas práticas estratégicas.

Aprofundando Estratégia como Prática, Jarzabkowski (2005, p.11), dentro do conceito de uma estratégia socialmente construída entre os atores sociais, ressalta que esta é marcada pela presença de três pontos focais, com diferentes ângulos e possibilidades de estudos em Estratégia como Prática: Praticantes, Práticas e Práxis. A relação entre esses pontos é articulada pela Figura 1: 
Figura 1: Representação de práxis, praticantes e práticas

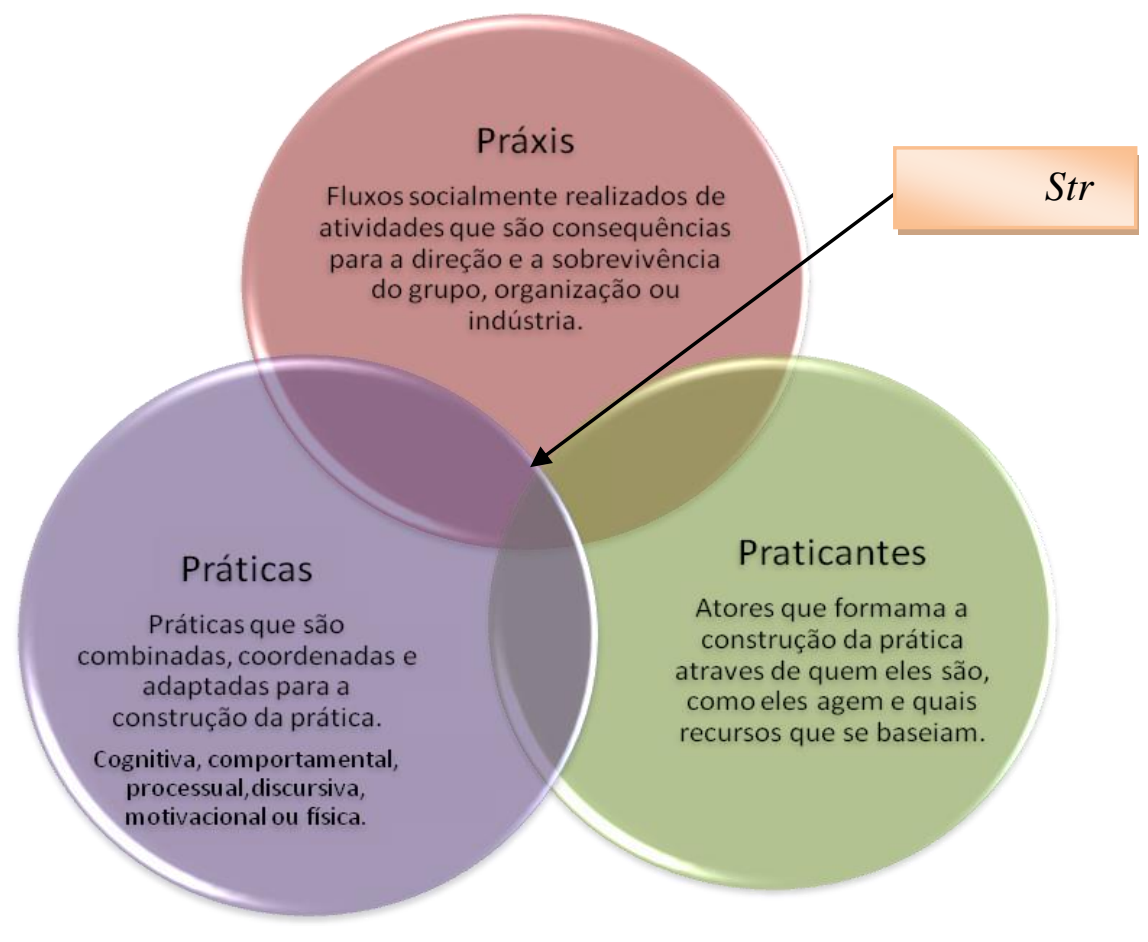

Fonte: JARZABKOWSKI, P., BALOGUN, J.; SEIDL, D. Strategizing: the challenges of the practice perspective. Human Relations, v.60, n.5, 2007.

A figura 1 de Jarzabkowski $(2005,2007)$ ressalta os três pontos principais de enfoque da Estratégia como Prática e suas possíveis intersecções de estudo, que podem ser articuladas dependendo do enfoque do pesquisador.

A práxis trata-se, segundo Jarzabkowski, Balogun e Seidl (2007, p.8) de um termo utilizado para descrever toda ação humana. Se preocupa em investigar o que acontece na sociedade e o que as pessoas estão fazendo em determinado campo de pesquisa. Para os autores, a práxis refere-se a interligação entre as ações de diferentes indivíduos em grupos dispersos que, socialmente, politicamente e economicamente, atuam ou contribuem em uma determinada organização.

Os autores destacam sua capacidade multinível de atuação, dada, logicamente a natureza pluralista da sociedade. Sendo assim, uma mesma práxis pode ser estudada em paralelo, divergentes, entrecruzadas, e concorrentes com fluxos que impactam uns sobre os outros.

A outra parte do modelo, as práticas, para Jarzabkowski, Balogun e Seidl et al (2007, p.9) podem ser relacionadas a tipos de comportamento rotinizados, frutos de um 
conjunto de aspectos como padrões culturais e mentais, conhecimentos, estados de emoção e motivação. Os autores enfocam que:

a utilização de tais práticas está intrinsecamente ligado ao "fazer", pois fornecem os recursos comportamentais, cognitivos, procedimentais, discursivo e físicos através da qual vários atores são capazes de interagir socialmente, a fim de realizar atividade coletiva. (JARZABKOWSKI, BALOGUN e SEIDL, 2007, p.9)

O que os autores ressaltam é que as práticas não são imutáveis e rígidas. Pelo contrário, as práticas são diversas e variam conforme seu poder de influência no campo onde estão atuando, não havendo um padrão único.

Jarzabkowski, Balogun e Seidl (2007, p.9) justificam que as práticas são uma importante fonte de análise de como a estratégia é formada, construída e desenhada pelos estrategistas, como se altera ao longo do tempo e como pode influenciar a práxis dos indivíduos a fim de influenciar o surgimento de novas práticas no campo em diferentes níveis.

Por fim, os praticantes são os profissionais. Para Jarzabkowski, Balogun e Seidl (2007, p.10) os praticantes da estratégia "são os atores, aqueles indivíduos que recorrem a práticas para agir”. Os praticantes estão relacionados com a práxis e com as práticas exercidas nas organizações. Ambas estão relacionadas ao poder de agência que os praticantes possuem em determinado campo.

Para os autores, os praticantes possuem alvo fundamental de análise da formação da estratégia, pois dependendo de sua maneira de se comportar, pensar, emocionar, conhecer e agir dentro de uma sociedade agregando isso a seus interesses, a fim de se adaptar e ao mesmo tempo influenciar uma determinada unidade social, faz com que sejam participantes ativos na construção das estratégias.

Na visão desses autores, os praticantes "moldam atividade estratégica através de quem eles são, como agem e quais as práticas que basear-se nessa ação. " (JARZABKOWSKI, BALOGUN E SEIDL,2007, p.10)

Dessa forma, o strategizing, fruto da combinação casada e da intersecção entre práxis, práticas e praticantes implica em realmente entender o fazer estratégia, investigando como ela é pensada e executada nos multiníveis organizacionais. Dentre os níveis organizacionais encontram-se, segundo Carriéri, Silva e Junquilho (2008, p.4) o nível micro (das ações cotidianas), meso ( da cultura da organização, dos sistemas de 
liderança, entre outros) e macro (do ambiente de atuação), que se inter relacionam e produzem contextos diferentes, que naturalmente exigem padrões diferentes de ações a serem estudadas pela Estratégia como Prática.

O strategizing, como cita Jarzabkowski (2005, p.34), é visto como a habilidade de utilizar, adaptar e manipular recursos que estão à mão para participar na definição da atividade de estratégia ao longo do tempo.

$\mathrm{Na}$ visão da autora, investigar a estratégia como uma prática social significa focar nas pessoas e como as práticas estratégicas desenvolvidas em sua ações cotidianas modificam a realidade social de seu campo.

Whittington (2003, p.4), por fim, destaca que a perspectiva prática está interessada em atividades concretas, que estão presente no trabalho cotidiano, em salas de reuniões, em telefones e na frente de telas de computador.

Sendo assim, adiante este estudo demonstrará algumas das características das organizações universitárias para, em seguida, relacionar as implicações da estratégia como prática para esse campo.

\section{Universidade como organização complexa e diferenciada}

As universidades são identificadas por vários autores da literatura brasileira e estrangeira, entre eles Etzioni (1972), Cohen, March e Olsen (1972), Weick (1976), Baldrige (1983) e Meyer Jr. (2007) como organizações diferenciadas das demais burocracias tradicionais, sendo caracterizadas como sistemas altamente complexos.

Entre as razões para essa afirmação, segundo os autores, estão características particulares que essas centenárias organizações possuem e a profunda importância que representam para o desenvolvimento da sociedade, já que sua economia está pautada essencialmente no conhecimento.

Meyer Jr (2007, p.232) ressalta que as Universidades são chamadas de organizações complexas, por exigirem maior atenção e análise ao seu processo estratégico, já que seu foco maior é a construção conhecimento, ou seja, "sua economia está fundamentada no capital intelectual e na criatividade."

Baldridge et al. (1983), analisando as organizações educacionais destaca que estas possuem alto grau de ambigüidade por possuírem objetivos vagos, difusos e incertos, já que raramente possuem uma só missão. Além disso, contam com um cliente 
com necessidades específicas, apresentando tecnologia deficitária e confusa, corpo altamente especializado e fragmentado por área de competência profissional, sendo, por fim, altamente vulnerável a fatores externos.

Etzioni (1972, p.27) complementa que as Universidades são organizações que apresentam múltiplas finalidades, dentre elas ensino e pesquisa, transmissão e criação de conhecimento em meio a profissionais altamente especializados. Em função disso, a existência de conflitos internos são inevitáveis já que a pluralidade de objetivos, aliados ao jogo político, emana tensões pessoais aos membros da organização.

O autor ressalta que há um centro de poder regido pelos especialistas em atuação, onde cada um atua com autonomia de decisão, segundo seu conhecimento; e um segundo centro de poder, regido pelas normas, regulamentos e estatutos da universidade. Esse primeiro, caracterizado pela determinada autonomia e frouxidão nas ações dos especialistas em campo é conhecido como liberdade acadêmica, destacada também por Lockwood e Davies (1985) como uma das características básicas incorporadas ao meio interno de Universidades.

Mais focados ao estudo da dinâmica interna das Universidades e de seu processo decisório, Cohen, March e Olsen (1972) e Cohen e March(1974), utilizaram-se das expressões metafóricas "anarquia organizada" e "lata de lixo" para descrever sua realidade interna e seu processo decisório, respectivamente.

Primeiramente, como anarquia organizada, Cohen e March (1974) destacam que, em virtude de sua realidade complexa, a participação dos agentes componentes deste sistema se dá de maneira fluída. Melhor explicando, o próprio autor cita que:

$\mathrm{Na}$ universidade, percebida como uma anarquia organizada, cada indivíduo é visto como um tomador de decisões autônomo. Professores decidem se, quando e o que ensinar. Os alunos decidem se, quando e o que aprender. Os legisladores decidem se, quando e quem apoiar. Nem coordenação, nem de controle são praticados. Os recursos são alocados por qualquer processo, emergindo constantemente, mas sem acomodação explícita e sem referência a algum objetivo superordenado. As "decisões" do sistema são uma consequência produzida pelo próprio sistema, decididamente controlada por ninguém. ( Tradução de COHEN e MARCH, 1974, p.33)

Meyer Jr (2007, p.248) complementa que, como anarquia organizada, os autores estão se referindo aos vários elementos ou agentes que, dentro de uma Universidade, se 
inter-relacionam, de maneira ilógica, mediante conexões não lineares onde os resultados são no mínimo, imprevisíveis. Os profissionais exercem suas atividades de maneira semi autônoma, partindo do conhecimento de sua competência profissional e atuando de acordo com suas próprias aspirações.

Em relação ao processo decisório e a expressão "lata de lixo" cunhada por Cohen, March e Olsen(1972), pode-se afirmar que, de acordo com esses autores, as decisões em Universidades não resultam de uma atividade ordenada, mas que as oportunidades ou opções de escolha para decisões estão dispostas como em uma "lata de lixo", ou seja, misturadas em "um recipiente no qual as soluções, postas e rotuladas pelos participantes, aguardam problemas aos quais serão atreladas ou aplicadas" (MEYER Jr, 2007, p.250). O modelo lata de lixo prevê uma realidade distinta de uma burocracia organizada e complementa o conceito de uma anarquia organizada.

Na visão desses autores, o modelo decisório se apresenta de maneira diferenciada em Universidades, apresentando como característica principal a não linearidade e autonomia. Problemas e alternativas de escolha; histórico de decisões e ações já tomadas estão misturadas como se, de fato, estivessem em um recipiente onde gestores recorrem e resgatam para servir como base para futuras decisões estratégicas. Nas palavras de Cohen, March e Olsen (1972, p.1),os autores explicam que

\footnotetext{
Estudos recentes sobre universidades, uma forma familiar de anarquia organizada, sugerem que essas organizações podem ser vistas com algumas características, como: conjunto de soluções à procura de problemas, questões e sentimentos procurando situações de decisão, soluções à procura de questões às quais eles podem ser uma resposta $\mathrm{e}$ tomadores de decisão à procura de trabalho. (Tradução de COHEN, MARCH E OLSEN, 1972, p.1)
}

De acordo com esses autores, nas organizações universitárias, os agentes em campo possuem uma maior autonomia para ação, já que os centros de poder são distintos e divididos por área de competência profissional e a coordenação é praticamente inexistente. O sistema passa a ser articulado de maneira frouxa, apresentando, segundo Meyer Jr e Walter (2010, p.76) "fraca integração e interdependência entre os trabalhos acadêmicos".

Essa frouxidão faz com que pesquisadores estudem a realidade das organizações universitárias por outras óticas (SIENA,1993; BUNDT, 2000). Rebello, Erdmann e Coelho (2003) ressaltam que as universidades podem ser analisadas pela ótica da Teoria 
dos SAC's - Sistemnas Adaptativos Complexos, pela sua não linearidade, baixo acoplamento e interdependência entre seus agentes.

Nestes sistemas, segundo Agostinho (2003), vários agentes atuam simultaneamente, em direções não lineares, produzindo regularidades de comportamento, que, por muitas vezes, tornam-se as estratégias da organização.

Para a autora, a estratégia, nestes sistemas, é resultante do padrão estabelecido nas interações entre os agentes, que podem se alterar constantemente, emergindo novos padrões. Qualquer tipo de previsão que se deseje fazer sobre os comportamentos em um sistema adaptativo complexo será resultado de uma soma ou média dos comportamentos individuais dos agentes. Ou seja, os agentes, por meio de suas ações individuais e escolhas, definem seu comportamento e traçam seu caminho aleatoriamente, autoorganizando, pelos padrões emergentes, o sistema como um todo.

Trata-se do que Weick (1976) advoga como sendo sistemas frouxamente articulados, ou seja, as interações e as ações dos indivíduos estão sujeitas a interpretações variadas. As ações acontecem em vários sentidos, pela improvisação e pela interpretação das situações, não havendo, muitas vezes, claras relações causais com a intenção previamente deliberada pela organização, por que os agentes atuam de maneira semi-autônoma (MEYER, 2007).

Essa atuação semi-autônoma, em partes é dada, por que as Universidades são caracterizadas como uma organização profissional (MINTZBERG et al. 2006), onde a característica básica que as diferencia das demais organizações é o fato de ser composta de um corpo altamente especializado, que age segundo seu próprio conhecimento e criatividade.

A relação é diferente de um sistema altamente racional e justaposto, onde os indivíduos não atuam de maneira independente e as ações são rigorosamente relacionadas com um plano de intenções previamente estabelecidas (MEYER, 2007).

De acordo com autores como Meyer (2007), Baldrige (1983) e Weick (1976), as Universidades possuem características diferenciadas das demais burocracias tradicionais. Elas fogem a um comportamento racional de organização baseado em regras e regulamentos, em comportamentos padrões, em delimitações de áreas de competências e atribuições, em estruturas hierarquizadas com ênfase na competência técnica. As organizações universitárias tendem a ser mais fluidas ou articuladas de maneira frouxa. (WEICK, 1976, BALDRIDGE, 1983; MEYER, 2007) 
Em se apresentando desta maneira a literatura sobre organizações educacionais universitárias, é visto que são grandes os desafios gerenciais para essas organizações. Assim sendo, este estudo busca examinar como a estratégia como prática contribui para o estudo da formação das estratégias nessas organizações.

\section{A Prática da Estratégia em Universidades}

\section{A Estratégia como um Processo Racional, Político e Simbólico}

A literatura sobre estratégia é ampla e diversificada. Nesta, autores deixam explícito a existência de dimensões que a estratégia assume em diferentes contextos da sua gestão estratégica.

Destacam-se na literatura autores que reforçam que a estratégia pode ser resultado de um processo altamente racional, calculado e lógico, o que chamam de dimensão racional (ANSOFF,1993); de conflitos de interesse, barganhas e negociações constantes, o que chamam de dimensão política (CHAFFEE,1995); e de processos altamente simbólicos, marcados pelas crenças, valores e ritos de um grupo específico, o que denominaram de dimensão simbólica (COHEN e MARCH, 1974). Há, portanto, um conjunto de autores que defendem na literatura a existência de cada uma dessas dimensões expostas anteriormente.

Alguns ainda, como Keller (1997) e Meyer (2005) destacam que as estratégias podem ser resultante das três dimensões em conjunto, onde, em determinado contexto, pode predominar a dimensão mais racional, política ou simbólica. Essas dimensões se misturam durante seu processo estratégico, podendo, dependendo da complexidade de cada organização, predominar um tipo de dimensão em detrimento de outra.

Pela dimensão racional, retratada por autores clássicos como Porter (1986); Ansoff, McDonell (1993), a estratégia é fruto de um "processo racional, lógico de ordenar objetivos, decisões e o uso de recursos escassos de forma a orientar as ações em prol dos resultados pretendidos"(MEYER, MANGOLIM 2006, p.376).

Um estudo de Jarzabkowski (2003, p.40) em Universidades já identificou, por exemplo, na Universidade de Warwick, no Reino Unido, as principais atividades do comitê estratégico, onde ressaltou: elaborar um plano financeiro, tomar decisões estratégicas relativas ao desenvolvimento, crescimento e alocação de recursos, elaborar 
os planos de ação e controlar as principais áreas de ação estratégica da Universidade. A lógica é estritamente racional e linear, de planejamento e de seqüenciamento lógico.

Hardy e Fachin (2000, p.140), acrescentam que o papel do plano em Universidades é mais exercer influência em interações do que propriamente resolver questões pontuais e específicas. De certa forma, são as interações e as ações originadas das interpretações desses planos que influenciarão as práticas estratégicas, sendo esse o enfoque da Estratégia como Prática social.

Os autores complementam que "planos formais são pouco relevantes na maioria das Universidades, já que a descentralização do poder significa que a mudança se inicia passo a passo, de baixo para cima." (HARDY E FACHIN, 2000, p.140)

Na dimensão política, retratada por autores como Baldridge(1983), Bolman e Deal (2003) a estratégia pode ser percebida como um conjunto de negociações entre grupos de interesse dos quais o plano e a estratégia dependem fielmente de seus apoios.

Trata-se de disputas políticas, barganhas e manipulações. Planos Institucionais, por exemplo, de metas, objetivos e diretrizes em Universidades podem ser um instrumento basicamente de ordem lógica e racional, conforme visto acima, no entanto, revestido de um caráter essencialmente político entre os vários grupos de interesse acerca de apoio ou não a esse plano (MEYER, MANGOLIM 2006, p.376). Nestes casos, o plano pode significar uma mera legitimação da visão e dos interesses do grupo dominante na organização universitária, caracterizando fortemente a dimensão política.

Pela visão simbólica, retratada na literatura por autores como Schein (1992), Morgan (1996), as estratégias se formam a partir de um conjunto de interpretações feitas por cada praticante. Significa entender que muitas vezes o plano em Universidades, conforme Wildavsky (1975, apud Meyer 2006, p.379) "não é definido por aquilo que produz, mas pelo que simboliza". Uma estratégia formulada, estabelecida entre consensos de grupos, informada e clara simboliza uma gestão sólida e equilibrada, gerando boas significações aos stakeholders.

Conforme a literatura apresenta, a estratégia, ou o fazer estratégia - strategizing, pode ser identificado e examinado tanto pela perspectiva racional, política e simbólica, como fruto da interação das pessoas e algo que elas mesmas produzem a partir de suas interpretações e disposições para a ação em um determinado momento (WHITTINGTON,1996; 2002).

Em uma realidade altamente subjetiva, com paradoxos e ambigüidades como a das Universidades, as microatividades (são fundamentais para entendimento do 
processo estratégico, que ora será um processo mais racional, ora mais político e ora essencialmente simbólico.

\section{A Estratégia em uma Organização Profissional e Frouxamente Articulada}

Por se tratarem de organizações profissionais (Etzioni 1972; Mintzberg, 2004) as características das Universidades são diferenciadas das organizações tradicionais. Minztberg (2004, p.319) cita que nestas organizações "muitas das pedras filosofais da organização máquina, e do planejamento destro, desmoronam, especialmente as do controle de cima para baixo e da geração centralizada da estratégia”. Desejar que o planejamento formal se encaixe perfeitamente em uma organização profissional como Universidades seria como querer "encaixar os pinos quadrados do planejamento nos buracos redondos da organização".

Para Mintzberg (2004, p.319) essas organizações:

são visivelmente ligadas de forma flexível em seus núcleos operacionais, os professores ensinam e fazem pesquisa em isolamento quase completo entre si, especialmente entre departamentos[...]Tratam-se de sistemas diferentes e articulados de maneira mais "frouxa", totalmente opostos aos da organização máquina, onde o planejamento se dá pelo método convencional.

Neste tipo de organização profissional, a estratégia é formada na atuação dos próprios praticantes, considerando que os serviços específicos ficam a cargo dos profissionais em sua atuação individual, daí sua relevância para a Estratégia como Prática.

Hardy e Fachin (2000, p.143) já alertam que, pela complexidade existente nas Universidades, "se pode planejar edifícios, mas não se consegue planejar pessoas". Inevitalmente, neste caso, uma parte da estratégia será resultante de um composto formado pelas posturas individuais de ensino e pesquisa dos professores, emergindo constantemente.

Esse ponto é crucial para a análise da Estratégia como Prática e das microatividades em Universidades, já que, se tratando de organizações profissionais e na visão de Hardy e Fachin (2000), muito da prática estratégia será articulada pelos 
próprios praticantes (professores, decanos, coordenadores), que em alguns casos, serão os próprios estrategistas.

Trata-se do que chamou Weick (1976) de sistemas frouxamente articulados, onde cada unidade da Universidade atua de maneira semi-autônoma em suas decisões, agindo e moldando a estratégia de acordo com a sua racionalidade ou de um determinado grupo. São sistemas diferenciados de sistemas racionais e justapostos.

Orton e Weick (1990), utilizaram-se do conceito de sistemas frouxamente articulados (Loosely Coupled) para explicar as relações frouxas entre elementos internos das organizações educacionais, como entre meios e fins, entre processos e resultados, entre administradores e professores, entre professores e materiais, entre a administração e os membros da organização, entre professores e pais, entre professores e alunos e entre pais e reuniões escolares.

Para os autores, como organizações educacionais são sistemas frouxamente articulados (Orton e Weick (1990) o processo de formação das estratégias é fluido, conduzido por relação frouxa, diferentemente de outras organizações, onde todos se reportam a um chefe executivo e a relação é fortemente emparelhada ou justaposta.

Nessas organizações existem partes que estão interligadas, mas que de maneira frouxa se relacionam no sistema, já que cada parte apresenta uma dada autonomia e preserva uma identidade. Desta forma, as estruturas organizacionais podem ser concebidas como algo que as organizações fazem, e não apenas como algo que elas possuem. As interações entre os agentes, na execução de suas práxis e práticas, traduzem seus modos de adaptação e respostas ao ambiente, definindo sua estrutura organizacional. Trata-se de um conceito multidimensional, onde as conexões são consideradas dentro das organizações e as frouxidões se apresentam rotineiramente, por tratar de um sistema complexo, com múltiplas variáveis, centros de poder e ambigüidades.

Em sistemas frouxamente articulados, o papel da microatividade é fundamental, uma vez que não há uma relação entre objetivos traçados em Universidades e desempenho organizacional, ou seja, as atividades são conduzidas de maneira frouxa, de modo que há um hiato entre a intenção desejada por um plano e a ação realizada de fato pelos praticantes. Essa dicotomia entre intenção e ação é claramente retratada por Castor e Suga (1988).

Dessa forma, a formação "real" da estratégia (objeto de estudo da Estratégia como Prática) é resultante do conjunto dessas microatividades realizadas pelas pessoas, 
ou seja, pelo conjunto das práxis que agregadas compõem as práticas estratégicas dos praticantes.

Nestes sistemas, o estudo dessas microatividades possui profunda relevância já que a participação das pessoas é algo extremamente fluído e imprevisível. Vários grupos de interesse são responsáveis por uma decisão. Tanto gestores, colaboradores, especialistas e alunos estão integrados e em constante relação, cujo produto de ações muitas vezes não comporta relação com algum plano ou estratégia, mas pode tornar-se, no entanto, pós fato uma estratégia na organização.

Meyer (2007, p.249) destaca que "o grau de comprometimento dos diversos grupos quanto aos problemas a serem resolvidos, as alternativas de solução, as formas de decisão e as ações desenvolvidas são distintas entre os diversos participantes, caracterizando, portanto, um sistema frouxamente articulado."

Considerando a complexidade organizacional das Universidades, sua característica frouxamente articulada e sua burocracia profissional, fica claro que as estratégias consequentemente se desenvolverão nos níveis mais baixos da organização, sendo as pessoas (professores, coordenadores, e demais especialistas) os responsáveis por parte da formação da estratégia.

Em Universidades, os praticantes da estratégia estão em seus grupos interagindo constantemente, negociando e atuando em prol dos objetivos macros da organização. Agem racionalmente, politicamente e simbolicamente. Atuam em direções diversas, de uma certa forma que o sistema se auto organiza, pelas relações frouxas entre seus agentes

No tocante a Estratégia como Prática em Universidades, a questão principal é o foco de sua estratégia está em sua abordagem micro, na ação das pessoas em interação, no comprometimento, na rede de contatos, nas interpretações e disposições para a ação de cada praticante ao executar alguma prática estratégia (WHITTINGTON, JOHNSON, MELIN, 2004).

Para tanto, conforme objetivo deste estudo, a Figura 2 examina a contribuição da estratégia como prática para o estudo da formação das estratégias em Universidades. Para fins didáticos, se dividiu entre as questões estratégicas: estratégia e estrutura. $\mathrm{Na}$ realidade, todo o quadro corresponde a implicações de uma realidade única chamada Universidade.

Figura 02: Implicações da Estratégia como Prática para o estudo da formação das estratégias em Universidades 


\section{Universidades}

Múltiplas finalidades: ensino, pesquisa, transmissão e criação do conhecimento.

Base profissional: essencialmente intelectual,especializada e que apresenta por característica principal de trabalho a individualidade.

Produto final: altamente intangível, o conhecimento.

Clientes: apresentam necessidades pessoais especiais e imprevisíveis.

Características principais: considerada como organização complexa; profissional;que apresenta alto grau de ambigüidade; tecnologia difusa e problemática; objetivos vagos, variados, incertos e conflitantes.

\begin{tabular}{|c|c|}
\hline Estratégi & Implicações da Estratégia como Prática para as Universidades. \\
\hline Racional & $\begin{array}{l}\text { Investigar que tipo de ações/práxis ou práticas resultaram do plano estratégico, já que há } \\
\text { um pressuposto racional de que declarações de missões, visões e objetivos orientam as ações de } \\
\text { maneira articulada e interferem no desempenho organizacional. }\end{array}$ \\
\hline
\end{tabular}

Politico

Investigar as práxis ou práticas que originam as decisões estratégicas. As reuniões, as barganhas, manipulações de grupos de interesse, jogos de poder e a influência das redes de relacionamentos. Grande parte das estratégias em Universidades surgem de grandes processos $-1 \ll:-\ldots$

Simbólic

Analisar que práticas estratégicas foram oriundas de crenças compartilhadas; que atividades são apoiadoras da estratégia macro e quais são repudiadoras; como os planos são interpretados e funcionam como justificativas para interações ou para demonstrar modernidade de

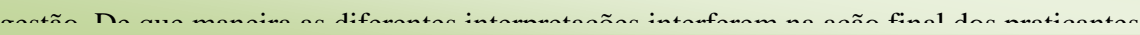

Estrutura

Sistema:

Frouxamente

Articulados

Dinâmic

a

Interna:Anarquias

Organizadas

Processo

Decisório:Modelo

de decisão Lata de

Lixo

Fonte: $\mathrm{O}$ autor
Implicações da Estratégia como Prática para as Universidades.

Investigar que relações existem entre as intenções planejadas e as ações executadas nas Universidades. Como os praticantes da estratégia decidem e tomam suas decisões em espaços semi-autônomos; ou como a "liberdade acadêmica" pode interferir na formação ou na execução da estratégia em organizações universitárias.

Investigar como os praticantes estão dispostos no interior das Universidades e como os grupos se interagem para formar as práticas estratégicas. A lógica de uma anarquia organizada não pressupõe um controle ou coordenação absoluta sobre as atividades. As pessoas interagem para direções diferentes e o sistema como um todo se auto-organiza. São indivíduos/grupos tomando decisões autônomas em direções imprevisíveis que encontram explicações na estratégia micro. "Professores decidem se, quando e o que ensinar. Os alunos decidem se, quando

Tratar como, em meio a uma realidade universitária altamente complexa, o processo decisório nas Universidades é uma combinacão de problemas, decisões e tomadores de decisão para a execução das ações em campo. Investigar como muitas das ações são executadas como base em decisões já tomadas para problemas similares. De fato, é como se houvesse um "recipiente" no qual as solucões, postas e rotuladas pelos participantes, aguardam problemas aos 


\section{Considerações finais}

Neste estudo, o objetivo foi examinar como a Estratégia como Prática contribui para o estudo de formação das estratégias em Universidades, organizações identificadas na literatura como complexas, profissionais e frouxamente articuladas.

A literatura sobre Estratégia como Prática agrega uma nova visão acerca do que realmente se passa no interior das organizações universitárias pelo foco nas microatividades e ênfase nos processos detalhados e práticas que constituem as atividades do dia a dia dessas organizacoes e que dizem respeito aos seus resultados estratégicos.

Pela ótica da Estratégia como Prática, logo se percebe que a formação da estratégia em uma organização altamente complexa não poderia ser diferente de um processo estratégico altamente complexo. O foco volta-se para as microatividades, analisando estratégias disseminadas em atos racionais, políticos e simbólicos. As estratégias estão dispostas em uma burocracia altamente especializada, que descentraliza o poder, deixando suas ligações frouxas e fluidas.

Examinar as Universidades pelas lentes da Estratégia como Pratica permite concluir que as estratégias surgem da interação entre os grupos, das negociações políticas, das barganhas, das interpretações do plano, e as ações são regidas pelos praticantes, segundo o seu melhor conhecimento e disposição para a ação.

Observa-se também que não há na literatura contribuições consistentes que demonstrem uma nítida relação entre os planos estratégicos e as ações dos indivíduos em campo, o que coloca sobre a Estratégia como Prática um grande desafio de pesquisa na busca por entender, de fato, como em níveis mais baixos, a estratégia se forma e se consolida, principalmente pela analise de atividades a nível micro.

A Estratégia como Prática contribui essencialmente para entender como as práticas estratégicas se formam nas Universidades, já que muitas delas independem de uma administração consistente ou de planos robustos.

Nestas organizações, o sistema assume características frouxamente articuladas, onde ação e intenção estão distantes e pouco controladas. Os centros de poder estão descentralizados aos praticantes da estratégia, separados por área de competência profissional.

Portanto, sistemas com essas caraterísticas demandam análises micros muito bem aprofundadas já que, como Whittington (2003) explica, grandes fenômenos se 
congregam em explicações micro, ou seja, o fazer estratégia consegue aproximar níveis macro e micro organizacionais.

Por fim, a Estratégia como Prática se revela em uma importante abordagem para se entender as Universidades, considerando que seu enfoque está nas práticas diárias dessas organizações, mesmo que, às vezes, essas pareçam invisíveis aos olhos de abordagens tradicionais. Seu entendimento proporciona ganhos significativos em termos de pesquisa na área de estratégia e contribui para cada vez mais se aproximar da realidade social dessas complexas e desafiantes organizações.

\section{Referências}

AGOSTINHO, M. E. Complexidade e Organizações : em busca da gestão autônoma. Atlas, Rio de Janeiro: Atlas, 2003.

ANSOFF, H. I; McDONELL, E.J. Implantando a Administração Estratégica. 2. ed. Tradução de Antonio Zoratto Sanvicente e Guilherme Ary Plonky. São Paulo: Atlas, 2003.

BALDRIDGE, J. V. Organizational characteristics of colleges and universities. In: BALDRIDGE,J. V.; DEAL, T. The dynamics of organizational change in educations. California: McCutchan Publishing, 1983.

BOLMAN, L.G.; DEAL, T.E. Reframing Organizations: artistic, choice and leadership .2. ed. San Francisco: Jossey-Bass, 2003.

BOURDIEU, P. Razões práticas: sobre a teoria da ação. Campinas: Papirus, 1996.

BUNDT, C. F. da C. Universidade: mudanças e estratégias de ação. Dissertação (Mestrado em Administração) - Centro Sócio-Econômico - Universidade Federal de Santa Catarina, Florianópolis, 2000. 114f.

CARRIERI, A. de P.; SILVA, A. R. L. da; JUNQUILHO, G. S. O fazer estratégia na gestão como prática social: articulações entre representações sociais, estratégias e táticas cotidianas nas organizações. In: XXXII ENCONTRO NACIONAL DOS PROGRAMAS DE PÓSGRADUAÇÃO E PESQUISA EM ADMINISTRAÇÃO, 2008: Rio de janeiro. Anais eletrônicos: Rio de Janeiro, 2008.

CASTOR, B.V. J.; SUGA, N. Planejamento e ação planejada: o difícil binômio. Revista de Administração Pública, Rio de Janeiro, v.22, n.1, pp.104-122, jan./mar. 1988.

CHAFFEE, E. Three Models of Strategy. Academy of Management Review, vol. 10, n. $1,1985$. 
COHEN, M.; MARCH, J. Leadership and Ambiguity: The American College President. 2a.ed. Boston: Harvard Business School, 1974.

COHEN, M. D.; MARCH, J. G.; OLSEN, J.P. A Garbage Can Model of Organizational Choice. Administrative Science Quarterly, Ithaca, v. 17, n. 1, p. 1-25, Mar. 1972.

ETZIONI, A. Organizações Modernas. 2. ed. Tradução de Miriam L. Moreira Leite. São Paulo: Livraria Pioneira, 1972.

GIDDENS,A. A Constituição da Sociedade. São Paulo: Martins Fontes, 2003.

GOLSORKHI, D. et al. Introduction: what is strategy as practice ? In: GOLSORKHI, D.; ROULEAU L, SEIDL D, VAARA E. Cambridge Handbook of Strategy as Practice. Cambridge: Cambridge University Press, 2010.

HARDY, C.; FACHIN, R. Gestão estratégica na universidade brasileira - teoria e casos. 2. ed. Porto Alegre: Editora da Universidade, 2000.

JARZABKOWSKI, P. Strategic Practices: An activity theory perspective on continuity and change. Journal of Management Studies, v.40, n.1, 2003.

JARZABKOWSKI, P. Strategy as practice: an activity-based approach. London: Sage, 2005.

JARZABKOWSKI, P., BALOGUN, J.; SEIDL, D. Strategizing: The Challenges of the Practice Perspective. Human Relations, v.60, n.5, 2007.

KELLER, G. The Best of "Planning for higher education." Ann Arbor, MI: Society for College and University Planning, 1997.

LOCKWOOD, G.; DAVIES, J. Universities: The management Challenge. Windsor: SRHE/NFER- Nelson, 1985.

MEYER Jr, V. Planejamento Universitário: ato racional, político ou simbólico. Um estudo de Universidades Brasileiras. Revista Alcance, n. 12, v. 3, p.373-390, 2005.

MEYER JR., V.; MANGOLIM, L. Estratégia em universidades privadas: estudo de casos. In: $30^{\circ}$ Encontro nacional dos programas de pós-graduação em administração, 2006, Salvador. Anais... Salvador: ENANPAD, 2006.

MEYER JR., V. A escola como organização complexa. In: EYNG, A. M.; GISI, M.

L. (orgs.). Políticas e Gestão da Educação Superior: desafios e perspectivas. Ijuí:Unijuí, 2007.

MEYER JR., V.; WALTER, S.A. Estratégias Acadêmicas: análises de uma escola de administração. In: SILVEIRA, A.; DOMINGUES, M. J. C. S. (coords.). Reflexões sobre Administração Universitária e Ensino Superior. Curitiba: Juruá, 2010.

MINTZBERG, H. Ascensão e queda do planejamento estratégico. Porto Alegre: Bookman, 2004. 
MINTZBERG, $\mathrm{H}$. et al. O processo da estratégia: conceitos, contextos e casos selecionados. 4. ed. Tradução de Luciana de Oliveira da Rocha. Porto Alegre: Bookman:2006.

MORGAN, G. Imagens da organização. São Paulo, Atlas, 1996.

ORTON, J. D. ; WEICK, K. E. Loosely coupled systems: a reconceptualization. Academic of Management Review, vol 15, n², p.203-223, 1990.

PORTER, M. Estratégia competitiva: técnicas para análise da indústria e da concorrência. Rio de Janeiro: Campus, 1986.

REBELO, L. M. B.; ERDMANN, R. H.; COELHO, C. S. R. Contribuições da Teoria da Complexidade ao Processo de Planejamento Estratégico em Universidades. In: III Colóquio Internacional Sobre Gestión Universitária En América Del Sur, 2003. Buenos Aires, Argentina

SCHEIN, E. Organizational culture and leadership. San Francisco: Jossey-Bass, 1992.

SIENA, O. Tipos de racionalidade na lógica de ações de dirigentes em organizações universitárias brasileiras. Florianópolis: UFSC,1993. Dissertação de Mestrado. Programa de Pós-graduação em Administração, Universidade Federal de Santa Catarina. Curitiba, 1993. Disponível em: <https://repositorio.ufsc.br/xmlui/bitstream/handle/123456789/75862/90164.pdf?sequen

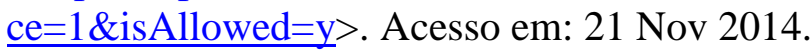

WEICK, K. E. Educational organization as loosely coupled systems. Administrative Science Quarterly, vol 21, p.1-19, 1976.

WHITTINGTON, R. Strategy as practice. Long Range Planning. v. 29, n. 5, p. 731735 , 1996.

. O que é estratégia. São Paulo: Pioneira Thomson Learning, 2002.

The work of strategizing and organizing: For a practice perspective.

Strategic Organization, 1/1: 117-125, 2003.

Completing the practice turn in strategy research. Organization Studies, v. 27, n.5, p. 613-634, 2006.

WHITTINGTON, R.; JOHNSON,G.; MELIN, L. The emerging field of strategy practice: some links, a trap, a choice, and a confusion. In: 2004 EGOS Colloquium, 2004, Ljubljana, Slovenia. 


\section{Como referenciar este artigo}

JUNIOR, Haroldo Andriguetto. A contribuição da estratégia como prática para o estudo da formação de estratégias em universidades. Revista on line de Política e Gestão Educacional, Araraquara/SP, v. 20, n.2, p. 337-358, 2016. Disponível em: <http://dx.doi.org/10.22633/rpge.v20.n2.9464>. ISSN: 1519-9029.

Submetido em: maio/2016

Aprovado em: jul/2016 